\title{
Tingkat Kesadaran Kepatuhan Pajak: Studi terhadap Badan Usaha Milik Desa
}

\author{
Pasca Dwi Putra ${ }^{1 *}$, Andri Zainal ${ }^{2}$, Charles Fransiscus Ambarita ${ }^{3}$, Endang Pratiwi ${ }^{4}$ \\ ${ }^{1 *}$ Pendidikan Bisnis, Fakultas Ekonomi, Universitas Negeri Medan, Indonesia \\ Jalan Willem Iskandar, Medan, Sumatera Utara, 20221 \\ ${ }^{2}$ Pendidikan Akuntansi, Fakultas Ekonomi, Universitas Negeri Medan, Indonesia \\ Jalan Willem Iskandar, Medan, Sumatera Utara, 20221 \\ ${ }^{3}$ Pendidikan Ekonomi, Fakultas Ekonomi, Universitas Negeri Medan, Indonesia \\ Jalan Willem Iskandar, Medan, Sumatera Utara, 20221 \\ Akuntansi, Fakultas Ekonomi dan Bisnis, Universitas Medan Area, Indonesia \\ Jl Setia Budi No 79 B, Medan, Sumatera Utara, 20112 \\ E-mail: sgacenter@gmail.com ${ }^{1 *}$
}

\begin{abstract}
ABSTRAK
Kepatuhan pajak merupakan tujuan dari pemerintah agar tercapai target pajak yang diharapkan. Dalam mencapai kepatuhan tersebut, pemerintah memberikan tarif pajak yang rendah untuk menstimulasi UMKM untuk patuh membayar hutang pajak. Pada sisi lain, pajak merupakan beban bagi UMKM dikarenakan merupakan pengeluaran kepada pemerintah yang dipotong dari pendapatan bersih sehingga wajib pajak mencari cara agar pajak yang dibayarkan rendah. Data dikumpulkan melalui penyebaran kuisioner dan wawancara. Hasil penelitian menunjukkan bahwa berdasarkan karakteristik responden baik jenis kelamin, tingkat Pendidikan, dan jenis usaha tidak menunjukkan perbedaan dalam menentukan kepatuhan wajib pajak. Disamping itu, pengetahuan mengenai regulasi perpajakan dan kesadaran dalam membayar pajak sangatlah penting dalam mencapai kepatuhan pajak dimana hasilnya menunjukkan pengaruh yang signifikan. Pada akhirnya, transparansi dan akuntabilitas penggunaan pajak merupakan informasi yang dibutuhkan dalam mencapai kepatuhan bagi BUMDes dalam meningkatkan kepatuhan membayar pajak.
\end{abstract}

Kata Kunci: Kepatuhan Pajak; Pemahaman Pajak; Kesadaran Pajak; UMKM; BUMDes.

\begin{abstract}
Tax compliance is the purpose of the Government in order to achieve the expected tax target. In achieving such compliance, the Government provides low tax rates to stimulate SMES to comply with tax debts. On the other hand, tax is a burden for SMES because it is an expense to the government that is deducted from net income so that taxpayers are looking for ways that taxes are paid low. Data is collected through the dissemination of questionnaire and interviews. The results showed that based on the characteristics of both genders, education levels, and business types did not indicate a difference in determining taxpayer compliance. In addition, knowledge of tax regulation and awareness in paying taxes is crucial in achieving tax compliance where the results show significant influence. Ultimately, transparency and accountability for the use of tax is the information needed to achieve compliance for BUMDes in improving the compliance of paying taxes.
\end{abstract}

Keywords: Tax compliance; tax understanding; tax awareness; SMEs; BUMDes. 


\section{PENDAHULUAN}

Pajak merupakan sumber pendapatan yang besar bagi suatu negara baik itu negara berkembang maupun negara maju (Aladejebi, 2018; AlAdham et al., 2016; Nurkhin et al., 2018; Savitri \& Musfialdy, 2016). Adapun penggunaannya untuk membiayai kegiatan seharihari dari negara seperti memberikan pelayanan, membangun fasilitas kesehatan, sekolah, dan umum serta memberikan kepastian aman kepada masyarakat sehingga tercapai kesejahteraan social (Fagariba, 2016; Febriani \& Kusmuriyanto, 2015). Adapun sumber pendapatan yang berasal dari pajak dapat berupa potongan pendapatan dari orang pribadi atas pendapatan yang diperolehnya dan pendapatan yang berasal dari badan usaha. Setiap tahunnya, pemerintah mempunyai target pencapaian pajak yang tujuannya sebagai sumber pendapatan yang akan digunakan untuk membiayai aktivitas keseharian ditahun depan. Salah satu sector yang memberikan kontribusi terbesar terhadap pendapatan yang berasal dari pajak adalah usaha kecil dan menengah (UMKM) dimana usaha ini dibentuk oleh sekelompok masyarakat dengan modal yang kecil dengan memanfaatkan sumber daya yang dimiliki dan modal yang kecil. Berdasarkan penelitian yang dilakukan (Aladejebi, 2018; Atawodi \& Ojeka, 2012; Daniel \& Faustin, 2019; Naicker \& Rajaram, 2018) menunjukkan bahwa UMKM sangat penting dalam membangun perekonomian suatu negara dimana memberikan kontribusi yang besar terhadap pendapatan. Disamping itu, UMKM juga berperan penting dalam mengurangi jumlah kemiskinan dalam suatu negara melalui penciptaan lapangan kerja sehingga masyarakat tidak bergantung kepada perusahaan besar (Aribaba et al., 2019; Hamid et al., 2010; Hohenwarter \& Ll, n.d.; Naicker \& Rajaram, 2018). Salah satu negara berkembang yang memberikan perhatian serius terhadap perkembangan UMKM yaitu Indonesia. Indonesia memiliki sumber daya alam yang melimpah tetapi pemanfaatannya belum maksimal. Oleh karena itu, melalui Kementerian Desa, Pembangunan Daerah Tertinggal dan Transmigrasi menggalakkan pemanfaatan sumber daya yang dimiliki desa dengan memanfaatkan masyarakat membentuk UMKM berupa Badan Usaha Milik Desa (BumDes). Diharapkan melalui pembentukan BumDes ini akan memberikan kontribusi yang besar berupa pajak kepada pemerintah. Sebelumnya pemerintah telah menetapkan pajak bagi UMKM sebesar 1\% melalui Peratuan Pemerintah No 46 Tahun 2016 dengan omzet sampai dengan 4,8 M/ tahun. Melalui peraturan tersebut, pada tahun 2016, pemerintah memperoleh pendapatan sebesar 57,48\%. Tetapi hal yang mengejutkan terjadi pada tahun 2017 dimana target pencapaian pajak yang diperoleh pada tahun tersebut hanya mencapai $60 \%$ dari total yang ditargetkan. Pada bulan Agustus 2019 menunjukkan pendapatan pajak yang berasal dari UMKM sebesar Rp. 6,9 triliun mengalami penurunan sebesar 21,8\% menjadi Rp. 4,84 triliun 
pada bulan Agustus 2019. Hal ini menunjukkan penurunan tarif pajak terhadap UMKM tidak memberikan dampak yang signifikan terhadap kesadaran pengusaha dalam membayar hutang pajak. Penurunan ini juga mengindikasikan kurang patuhnya dalam membayar pajak sehingga tidak tercapai target pajak yang diinginkan. Oleh karena itu, pemerintah harus mencari cara agar adanya peningkatan pendapatan pajak yang berasal dari UMKM dengan mengeluarkan Peraturan Pemerintah No 23 tahun 2018 mengenai tarif pajak untuk UMKM yang mengalami penurunan menjadi $0,5 \%$. Melalui peraturan tersebut pemerintah berharap adanya peningkatan pendapatan pajak yang berasal dari UMKM serta kesadaran dan kepatuhan UMKM dalam membayar pajak.

Disisi lain bagi pengusaha, pajak merupakan beban yang dipotong dari pendapatan bersih. Karena merupakan suatu beban, maka banyak pengusaha baik itu UMKM maupun besar yang enggan membayar pajak dengan mencari celah dari regulasi yang ada ataupun melakukan manipulasi terhadap laporan keuangan (Alstadsæter \& Jacob, 2013). Kurangnya kesadaran pentingnya pajak dalam membangun membuat tingkat kepatuhan dalam membayar pajak masih sangat rendah (Asrinanda \& Diantimala, 2018; Atawodi \& Ojeka, 2012). Hal ini dapat dilihat melalui perolehan pendapatan yang diterima pemerintah dari UMKM mengalami penurunan dari tahun 2016 ke 2017. Pentingnya kesadaran dalam menciptakan kepatuhan sangatlah penting dalam mencapai target pajak sehingga wajib pajak secara sadar membayar sejumlah hutang pajak yang dibayarkan (Savitri \& Musfialdy, 2016). Banyak faktor yang menyebabkan seseorang kurang patuh dalam membayar pajak seperti biaya kepatuhan yang dikeluarkan disamping hutang pajak yang akan dibayarkan (Eragbhe \& Modugu, 2014), pengetahuan peraturan perpajakan (Asrinanda \& Diantimala, 2018; Hastuti, 2014; Nurkhin et al., 2018), sosialisasi, kesadaran (Adimasu \& Daare, 2017; Febriani \& Kusmuriyanto, 2015; Suyanto \& Trisnawati, 2016), tingkat penjualan (AlAdham et al., 2016), dan kepercayaan masyarakat (Febriani \& Kusmuriyanto, 2015). Menurut Direktorat Jenderal Pajak (DJP) Kementerian Keuangan (Kemenkeu) bahwa tingkat kepatuhan wajib pajak pada tahun 2019 hanya sebesar $73 \%$ naik tipis $2 \%$ dari tahun sebelumnya yaitu $71 \%$ sehingga akan berdampak terhadap target capaian yang telah ditetapkan pemerintah (Nuridayu Yunus et al., 2017). Adapun tingkat kepatuhan ini masih dibawah standar yang telah ditetapkan yaitu sebesar 80\%. Masih rendahnya kepatuhan tersebut maka kiranya perlu melihat faktor yang mempengaruhi wajib pajak khususnya UMKM dalam membayarkan sejumlah pajak terutangnya. 
Dalam pencapaian target, sikap kepatuhan pajak sangatlah penting. Hal ini dikarenakan sikap yang taat terhadap peraturan perpajakan baik untuk membayar ataupun melaporkan. Dalam praktiknya, masih sangatlah sedikit sikap patuh terhadap pajak. Seperti yang dikeluarkan oleh Direktorat Jendral Paja (DJP) Kementerian Keuangan Republik Indonesia yang menunjukkan bahwa pada tahun 2019 kepatuhan pajak masyarakat Indonesia hanya sebesar $73 \%$ dari target kepatuhan pajak sebesar $80 \%$ walaupun menunjukkan kenaikan 2\% dari tahun lalu. Banyak cara yang dilakukan pemerintah untuk menstimulai agar masyarakat taat dan patuh terhadap peraturan perpajakan dimana salah satunya dengan program tax amnesty. Tetapi disisi wajib pajak, terdapat biaya kepatuhan yang harus dibayarkan untuk mencapai tingkatan kepatuhan pajak (Eragbhe \& Modugu, 2014) yaitu seluruh biaya yang harus dikeluarkan wajib pajak disamping hutang pajak kepada pihak otoritas. Sehingga hal itu yang menyebabkan banyak wajib pajak yang tidak patuh dalam membayar atau melaporkan pajak (Atawodi \& Ojeka, 2012).

Menurut Nurkhin et al., (2018) kepatuhan pajak merupakan kondisi bagi wajib pajak untuk memenuhi hutang pajaknya dan melaporkannya secara benar. Febriani \& Kusmuriyanto, (2015) juga menjelaskan bahwa kepatuhan pajak menunjukkan wajib pajak memenuhi seluruh kewajiban dan melaksanakan hak perpajakannya. Adapun kepatuhan disini yaitu patuh dalam mencatat dan melaporkan transaksi bisnis kepada regulator (Savitri \& Musfialdy, 2016). Eragbhe \& Modugu, (2014) juga menjelaskan bahwa dalam mencapai kepatuhan perpajakan perlu dikeluarkan biaya agar sesuai dengan peraturan perpajakan termasuk didalamnya biaya untuk memperoleh pengetahuan yang cukup, membayar konsultan pajak, penyelesaian berkaitan dengan hutang pajak dan lain-lain. Berdasarkan definisi diatas dapat disimpulkan bahwa kepatuhan pajak berkaitan bagaimana perilaku wajib pajak yang secara sadar patuh untuk membayar dan melaporkan hutang pajaknya kepada negara sesuai peraturan yang berlaku (Aladejebi, 2018). Banyak teori yang mendasari kepatuhan dalam membayar pajak. Salah satunya adanya the benefit theory yang diperkenalkan oleh John Stuart Mills tahun 1872. Teori ini menjelaskan bahwa seseorang akan patuh membayar pajak apabila memperoleh manfaat yang setara dari pajak yang dibayarkan (Elmi et al., 2015). Sedangkan menurut Optimal tax Theory menjelaskan bahwa pemerintah menentukan target pajak didasarkan pada kebutuhan untuk memenuhi program kerjanya (Aladejebi, 2018).

Dalam mencapai kepatuhan dari wajib pajak tersebut dibutuhkan transparansi dan akuntabilitas dari realisasi pajak yang diperoleh dari masyarakat. Menurut Febriani \& Kusmuriyanto, (2015) bahwa terdapat banyak faktor yang menyebabkan wajib pajak tidak 
patuh seperti (1) kurang pelayanan yang diberikan, (2) pembangunan yang tidak merata, (3) banyaknya penyalahgunaan anggaran seperti korupsi (Abiola \& Asiweh, 2012). Akibatnya, tidak tercapainya target kepatuhan yang telah ditetapkan oleh pemerintah. Oleh karena itu, perlu melihat faktor-faktor yag mempengaruhi wajib pajak dalam mencapai kepatuhan membayar pajak.

Adapun salah satu faktor yang mempengaruhi ketaatan dalam membayar pajak adalah pemahaman wajib pajak terhadap regulasi perpajakan. Pemahaman perpajakan menunjukkan kemampuan dari wajib pajak memahami dan mengetahui peraturan perpajakan (Febriani \& Kusmuriyanto, 2015; Hastuti, 2014) yang berlaku dimana kurangnya pemahaman pajak menyebabkan wajib pajak membayar dan melaporkan hutang pajaknya tidak sesuai dengan peraturan (Nkwe, 2012; Nurkhin et al., 2018). Sedangkan menurut (Pamuji, 2014) bahwa pemahaman perpajakan menunjukkan pengetahuan perpajakan yang dimengerti dengan baik dan benar oleh wajib pajak dan dapar menerjemahkan dan/atau menerapkan yang telah dipahami. Sehingga dapat disimpulkan bahwa pemahaman pajak disini adalah pengetahuan yang dimiliki wajib berkaitan dengan peraturan perpajakan sampai dengan mematuhinya melalui membayar hutang pajaknya. Semakin tinggi tingkat pemahaman wajib pajak mengenai pentingnya pajak bagi pembangunan negara maka semakin taatnya dalam membayarkan pajak. Hal ini didukung oleh penelitian yang dilakukan oleh (Asrinanda \& Diantimala, 2018; Nurkhin et al., 2018; Saad, 2014). Tetapi disisi lain, dalam mencapai pemahaman wajib pajak berkaitan dengan regulasi dibutuhkan sumber daya manusia yang terlatih dikarenakan menjadi suatu beban yang berat bagi usaha kecil dan menengah (Abrie \& Doussy, 2006), sedangkan kita ketahui di Indonesia UMKM banyak berasal dari masyarakat yang tingkat pendidikannya hanya sekolah menengah ke atas sehingga hal ini menjadi permasalahan serius bagi UMKM maupun pemerintah dalam mencapai ketaatan dalam membayar pajak (Kim \& Im, 2017; Naicker \& Rajaram, 2018; Newman et al., 2018). Oleh karena itu, dapat dirumuskan hipotesis sebagai berikut:

H1: Terdapat pengaruh yang signifikan pemahaman perpajakan terhadap kesadaran membayar pajak.

Faktor lain yang mempengaruhi UMKM patuh dalam membayar pajak adalah kesadaran. Kesadaran disini berkaitan dengan pengetahuan mengenai pentingnya pajak untuk membangun negara (Nuridayu Yunus et al., 2017). Menurut (Wicaksono, 2016) bahwa kesadaran membayar pajak merupakan penilaian positif masyarakat wajib pajak terhadap pelaksanaan fungsi negara oleh pemerintah dimana menggerakkan masyarakat untuk mematuhi kewajibannya dalam membayat pajak. Berdasarkan PP No. 46 Tahun 2013 
menunjukkan bahwa penghasilan dari usaha yang diterima wajib pajak dimana terdapat potensi besar diperoleh dari Usaha Mikro Kecil dan Menengah (UMKM). Apabila wajib pajak mengetahui pentingnya pajak maka mereka akan sadar dan membayar hutang pajak (Aladejebi, 2018; Savitri \& Musfialdy, 2016). Kesadaran membayar pajak berkaitan dengan sikap seseorang yang secara sukarela untuk patuh dan taat dalam membayar pajak (Adimasu \& Daare, 2017). Seperti penelitian yang dilakukan oleh (AlAdham et al., 2016; Nurkhin et al., 2018; Suyanto \& Trisnawati, 2016) menunjukkan bahwa pentingnya kesadaran dalam membayar pajak akan meningkatkan kepatuhan dalam membayar pajak. Berdasarkan penjelasan diatas maka hipotesis penelitian ini adalah:

H2: Terdapat pengaruh yang signifikan kesadaran membayar pajak terhadap kepatuhan membayar pajak.

\section{METODE PENELITIAN}

Penelitian ini bertujuan untuk melihat pengaruh dari pemahaman wajib pajak dan kesadaran membayar pajak terhadap kepatuhan wajib pajak. Data penelitian diperoleh dari data primer melalui penyebaran kuisioner kepada pengusaha UMKM khususnya BUMD. Lokasi penelitian dilakukan di 3 kabupaten besar pada Provinsi Sumatera Utara. Metode pengumpulan data menggunakan kuisioner dan interview terhadap responden. Kuisioner terdiri dari pertanyaan terbuka dan tertutup yang disusun agar responden mudah memahami. Adapun kuisioner didasarkan pada pengembangan pendapat ahli yang sebelumnya telah dilakukan uji validitas dan reliabilitas. Lokasi penelitian dilakukan di 3 kabupaten besar pada Provinsi Sumatera Utara. Adapun 3 kabupaten itu yaitu Kabupaten Deli Serdang, Kabupaten Langkat, Kabupaten Serdang Bedagai. Populasi pada penelitian ini adalah UMKM yang terdapat di desa pada 3 kabupaten tersebut. Sampel dipilih dengan menggunakan metode probabilitas sampling. Sampel pada penelitian ini merupakan usaha kecil dan menengah yang dibangun menggunakan dana desa tujuannya bagaimana pemanfaatan dana desa untuk meningkatkan kesejahteraan masyarakat. Jumlah sampel pada penelitian ini adalah 88 yang terdiri dari Kab. Deli Serdang sebanyak 30, Kab. Langkat 27, dan serdang bedagai 31. Pengujian hipotesis dengan menggunakan uji beda, uji anova. Metode analisis data yang digunakan adalah regresi linear berganda dimana bertujuan untuk melihat pengaruh pemahaman wajib pajak dan kesadaran membayar pajak terhadap kepatuhan wajib pajak. Adapun rumusan pengujian hipotesis dapat dilihat sebagai berikut:

$$
\mathrm{Y}=\mathrm{a}+\mathrm{b}_{1} \mathrm{X}_{1}+\mathrm{b}_{2} \mathrm{X}_{2}
$$


Keterangan:

$\mathrm{Y}=$ Kepatuhan wajib pajak

$\mathrm{X}_{1}=$ Pemahaman wajib pajak

$\mathrm{X}_{2}=$ Kesadaran wajib pajak

$\mathrm{a}=$ Konstanta

$\mathrm{b}_{1}, \mathrm{~b}_{2}=$ koefisien regresi

\section{HASIL DAN PEMBAHASAN}

Penelitian dilakukan pada Usaha Micro Kecil dan Menengah yang dikembangkan oleh desa yaitu BUMDes di 3 kabupaten besar yaitu Kabupaten Langkat, Kabupaten Deli Serdang, dan Kabupaten Serdang Bedagai.

Tabel 1. Jenis Usaha Mempengaruhi Kepatuhan Pajak

\begin{tabular}{lcrrrr}
\hline Source & $\begin{array}{c}\text { Type III Sum of } \\
\text { Squares }\end{array}$ & Df & Mean Square & F & \multicolumn{1}{l}{ Sig. } \\
\hline Corrected Model & $1278.499^{\mathrm{a}}$ & 12 & 106.542 & 0,679 & 0,766 \\
Intercept & 60010.333 & 1 & 60010.333 & 382,348 & 0,000 \\
$\mathrm{JU}$ & 979.022 & 2 & 489.511 & 3,119 & 0,050 \\
$\mathrm{P}$ & 88.627 & 5 & 17.725 & 0,113 & 0,989 \\
$\mathrm{JU} * \mathrm{P}$ & 333.286 & 5 & 66.657 & 0,425 & 0,830 \\
Error & 11771.399 & 75 & 156.952 & & \\
Total & 239395.000 & 88 & & & \\
Corrected Total & 13049.898 & 87 & & & \\
\hline
\end{tabular}

a. R Squared $=.098$ (Adjusted R Squared $=-.046$ )

Sumber: data diolah, 2020

Berdasarkan table 1 diatas menunjukkan bahwa jenis usaha tidak mempengaruhi wajib pajak dalam menjalankan kewajibannya dalam mematuhi pajak. Hal ini dilihat dari tingkat signifikan dari hasil yang menunjukkan nilai diatas $5 \%$.

Tabel 2. Uji Beda Antara Tingkat Pendidikan Dengan Kepatuhan Wajib Pajak

\begin{tabular}{cccc}
\hline Levene Statistic & df1 & df2 & Sig. \\
\hline $0,332^{\mathrm{a}}$ & 4 & 82 & 0,855 \\
\hline
\end{tabular}

a. Groups with only one case are ignored in computing the test of homogeneity of variance for Kepatuhan Pajak.

Sumber: Data Diolah, 2020

Berdasarkan tabel 2 diatas menunjukkan ada atau tidaknya perbedaan antara tingkat Pendidikan dengan tingkat kepatuhan wajib pajak dalam membayar pajak. Hasil menunjukkan tingkat signifikan sebesar 0,855 yang artinya tidak menunjukkan perbedaan antara tingkat Pendidikan terhadap kepatuhan pajak. Sehingga dapat disimpulkan bahwa tingkat Pendidikan seseorang tidak menunjukkan perbedaan terhadap kepatuhan membayar pajak. 
Tabel 3. Tingkat Pendidikan Mempengaruhi Kepatuhan Pajak

\begin{tabular}{lrrrrr}
\hline & Sum of Squares & Df & Mean Square & F & \multicolumn{1}{c}{ Sig. } \\
\hline Between Groups & 43,741 & 5 & 8,748 & 0,055 & 0,998 \\
Within Groups & 13006,156 & 82 & 158,612 & & \\
Total & 13049,898 & 87 & & & \\
\hline
\end{tabular}

Sumber: Data diolah, 2020

Berdasarkan table 3 diatas menunjukkan bahwa tingkat Pendidikan tidak berpengaruh signifikan terhadap kepatuhan pajak. Sehingga bukanlah tingkat Pendidikan yang mempengaruhi seseorang dalam mematuhi peraturan perpajakan.

Sebelumnya, telah dijelaskan hubungan antara karakteristik responden terhadap tingkat kepatuhan pajak. Berdasarkan pengujian dapat dilihat bahwa karakteristik responden baik jenis kelamin, jenis usaha, maupun tingkat Pendidikan menunjukkan tidak terdapat pengaruh terhadap kepatuhan wajib pajak. Berikut melihat faktor-faktor yang mempengaruhi kepatuhan wajib pajak didasarkan pada pemahaman dan kesadaran wajib pajak.

Tabel 4. Correlation Pearson

\begin{tabular}{llrrr}
\hline & & $\begin{array}{c}\text { Pemahaman } \\
\text { Perpajakan }\end{array}$ & Kesadaran & $\begin{array}{c}\text { Kepatuhan } \\
\text { Pajak }\end{array}$ \\
\hline \multirow{3}{*}{ Pemahaman Perpajakan } & Pearson Correlation & 1 & $0,725^{* *}$ & $0,783^{* *}$ \\
& Sig. (2-tailed) & & 0,000 & 0,000 \\
& $\mathrm{~N}$ & 88 & 88 & 88 \\
\multirow{5}{*}{ Kesadaran } & Pearson Correlation & $0,725^{* *}$ & 1 & $0,665^{* *}$ \\
& Sig. (2-tailed) & 0,000 & & 0,000 \\
\multirow{3}{*}{ Kepatuhan Pajak } & $\mathrm{N}$ & 88 & 88 & 88 \\
& Pearson Correlation & $0,783^{* *}$ & $0,665^{* *}$ & 1 \\
& Sig. (2-tailed) & 0,000 & 0,000 & 88 \\
\hline
\end{tabular}

**. Correlation is significant at the 0.01 level (2-tailed).

Sumber: data diolah 2020

Berdasarkan pengujian terhadap 88 responden pemilik BUMDes menunjukkan bahwa secara keseluruhan korelasi antara variable independent terhadap variable dependen samasama kuat. Hal ini dilihat dari korelasi pemahaman perpajakan terhadap kepatuhan pajak memiliki nilai 0,783 yang menunjukkan bahwa hubungan yang kuat antara pemahaman pajak terhadap kepatuhan pajak. Kesadaran dalam membayar pajak juga menunjukkan nilai sebesar 0,665 dimana hasilnya menunjukkan bahwa kesadaran dalam membayar pajak akan meningkatkan kepatuhan dalam membayar pajak.

Pengujian hipotesis disini menunjukkan pengaruh pemahaman pajak dan kesadaran wajib pajak terhadap kepatuhan wajib pajak dalam membayar dan melaporkan pajak. Adapun responden penelitian ini berjumlah 88 orang dan berasal dari pemilik BUMDes di 3 
kabupaten. Berikut hasil pengujian korelasi antara variable dependen dengan variable independent.

Tabel 5. Koefisien Determinasi

\begin{tabular}{lllll}
\hline Model & R & R Square & Adjusted R Square & Std. Error of the Estimate
\end{tabular}

\begin{tabular}{lllll}
\hline 1 & $.795^{\mathrm{a}}$ & .632 & .624 & 7.512 \\
\hline
\end{tabular}

a. Predictors: (Constant), Kesadaran, Pemahaman Perpajakan

Sumber: Data Diolah, 2020

Berdasarkan tabel 5 diatas dapat dilihat nilai korelasi sebesar 0,795 yang menunjukkan hubungan korelasi antara pemahaman pajak dan kesadaran wajib pajak sangatlah kuat terhadao kepatuhan dalam membayar pajak. Disamping itu, nilai koefisien determinasi menunjukkan nilai sebesar 0,624 dimana 62,4\% kepatuhan pajak dipengaruhi pemahaman pajak dan kesadaran sedangkan sisanya pada variable lainnya. Pengujian hipotesis melihat bagaimana pengaruh secara parsial variable pemahaman perpajakan dan kesadaran wajib pajak terhadap kepatuhan wajib pajak dalam membayar pajak.

Table 6. Pengujian Hipotesis

\begin{tabular}{|c|c|c|c|c|c|c|}
\hline \multirow{2}{*}{\multicolumn{2}{|c|}{ Model }} & \multicolumn{2}{|c|}{ Unstandardized Coefficients } & \multirow{2}{*}{$\begin{array}{c}\text { Standardized } \\
\text { Coefficients } \\
\text { Beta }\end{array}$} & \multirow[t]{2}{*}{$\mathrm{t}$} & \multirow[t]{2}{*}{ Sig. } \\
\hline & & B & Std. Error & & & \\
\hline \multirow{3}{*}{1} & (Constant) & .789 & 4.334 & & .182 & .856 \\
\hline & Pemahaman Perpajakan & .840 & .127 & 633 & 6.628 & .000 \\
\hline & Kesadaran & .317 & .147 & .206 & 2.158 & .034 \\
\hline
\end{tabular}

a. Dependent Variable: Kepatuhan Pajak

Sumber: Data Diolah, 2020

Berdasarkan tabel 6 diatas menunjukkan bahwa pemahaman perpajakan dan kesadaran membayar secara parsial berpengaruh signifikan terhadap kepatuhan pajak pada BUMDes di Kabupaten Langkat, Kabupaten Deli Serdang, dan Kabupaten Serdang Bedagai. Hasil pengujian menunjukkan bahwa pemahaman pajak memiliki nilai signifikan sebesar 0,000 dan kesadaran dengan nilai 0,034 (dibawah 5\%) sehingga dapat ditarik kesimpulan bahwa dalam meningkatkan kepatuhan pajak diperlukan pemahaman dan kesadaran wajib pajak.

Pengujian hipotesis pada penelitian ini untuk melihat faktor yang mempengaruhi kepatuhan wajib pajak yang dilihat dari karakteristik responden, pengetahuan, dan kesadaran wajib pajak. Adapun karakteristik responden berupa jenis kelamin, jenis usaha, dan tingkat Pendidikan. Berdasarkan uji beda menunjukkan tidak terdapat perbedaan baik jenis kelamin, jenis usaha, dan tingkat Pendidikan terhadap tingkat kepatuhan dalam membayar pajak. Sehingga dapat dijelaskan bahwa baik laki-laki maupun perempuan tidak terdapat pengaruh yang signifikan terhadap penentuan kepatuhan wajib pajak. Hasil ini bertentangan dengan 
penelitian yang dilakukan (Aladejebi, 2018; Nurkhin et al., 2018) yang menunjukkan bahwa perempuan lebih patuh dibandingkan dengan laki-laki. Disamping itu, jenis usaha berupa jasa, dagang, maupun manufaktur tidak menunjukkan pengaruh yang signifikan terhadap kepatuhan dalam membayar. Tingkat Pendidikan juga tidak menunjukkan kepatuhan dalam membayar pajak. Sehingga disimpulkan berdasarkan penelitian yang dilakukan menunjukkan bahwa karakteristik responden tidak memberikan pengaruh terhadap kepatuhan wajib pajak dalam membayar dan melaporkan pajak usahanya khususnya BUMDes.

Pentingnya pemahaman dan kesadaran wajib pajak merupakan salah satu faktor dalam menentukan kepatuhan wajib pajak. Pemahaman perpajakan menunjukkan pengetahuan berkaitan dengan peraturan perpajakan yang didalamnya terdapat aturan dan sanksi terhadap wajib pajak. Sedangkan kesadaran wajib pajak merupakan keinginan dalam diri sendiri untuk membayar sejumlah hutang pajak yang wajib dibayarkan dan dilaporkan kepada negara. Berdasarkan hasil penelitian yang dilakukan menunjukkan bahwa pemahaman wajib pajak terhadap peraturan perundang-undangan menyebabkan wajib pajak taat dan patuh dalam membayar pajak. Hal ini dilihat dari bahwa pemahaman wajib pajak tentang peraturan perpajakan berpengaruh positif terhadap kepatuhan wajib pajak dalam membayar pajak. Hasil penelitian ini sejalan dengan penelitian yang dilakukan (Febriani \& Kusmuriyanto, 2015; Saad, 2014).

Disamping itu, kesadaran akan pentingnya pajak juga memberikan pengaruh terhadap kepatuhan dalam membayar dan melaporkan pajak. Hasil ini didukung oleh (AlAdham et al., 2016; Asrinanda \& Diantimala, 2018; Savitri \& Musfialdy, 2016) dimana kesadaran dalam membayar pajak memberikan pengaruh terhadap pelunasan hutang pajak. Disamping itu, rendahnya pendapatan yang diperoleh juga mempengaruhi kesadaran dalam membayar pajak dimana perusahaan yang memperoleh pendapatan yang rendah akan memberikan kesadaran yang rendah juga terhadap kepatuhan dalam membayar pajak. Adanya self-assessment dalam pembayaran dan pelaporan pajak menyebabkan wajib pajak harus memiliki pemahamanan dan kesadaran untuk pencapaian kepatuhan pajak (Adimasu \& Daare, 2017; AlAdham et al., 2016; Hastuti, 2014; Suyanto \& Trisnawati, 2016). Pada akhirnya, hasil penelitian ini memberikan kontribusi bahwa dalam mencapai kepatuhan membayar dan melaporkan diperlukan pemahaman dan kesadaran tidak melihat jenis kelamin, tingkat Pendidikan, ataupun jenis usaha (Nurkhin et al., 2018). Pentingnya pemahaman dan kesadaran akan memberikan dampak positif terhadap pembangunan negara yang didanai oleh pajak. 


\section{KESIMPULAN DAN SARAN}

Dalam pencapaian kepatuhan diperlukan pemahaman dan kesadaran dalam membayar pajak. Pajak digunakan untuk membangun dan membiaya kegiatan suatu negara. Pentingnya pemahaman berkaitan dengan regulasi dan kesadaran dari wajib pajak. Berdasarkan hasil penelitian menunjukkan bahwa kepatuhan wajib pajak tanpa mempertimbangkan jenis kelamin, jenis usaha, maupun tingkat Pendidikan tetapi pemahaman mengenai regulasi dan kesadaran dari dalam diri merupakan faktor utama dari wajib pajak untuk patuh membayar pajak. Faktor kelalaian dan salah penggunaan pajak untuk membangun negara merupakan salah satu faktor yang mempengaruhi sikap wajib pajak untuk patuh seperti salah sasaran, pembangunan yang tidak merata, korupsi dan faktor lainnya (Febriani \& Kusmuriyanto, 2015). Penelitian selanjutnya diharapkan menambahkan komponen keuangan yang mempengaruhi kepatuhan membayar pajak. Komponen kekuangan ini memberikan gambaran berkaitan dengan kondisi keuangan perusahaan dalam kepatuhan membayar pajak.

\section{REFERENSI}

Abiola, J., \& Asiweh, M. (2012). Impact of Tax Administration on Government Revenue in a Developing Economy - A Case Study of Nigeria. International Journal of Business and Social Science, 3(8), 99-113. www.ijbssnet.com

Abrie, W., \& Doussy, E. (2006). Tax compliance obstacles encountered by small and medium enterprises in South Africa. Meditari Accountancy Research, 14(1), 1-13. https://doi.org/10.1108/10222529200600001

Adimasu, N. A., \& Daare, W. J. (2017). Tax Awareness and Perception Of Tax Payers and Their Voluntary Tax Compliance Decision: Evidence from Inividual Tax Payers in SNRR, Ethopia. International Journal of Scientific and Research Publications, 7(11), 686. www.ijsrp.org

Aladejebi, D. O. (2018). Measuring Tax Compliance Among Small and Medium Enterprises in Nigeria. International Journal of Accounting and Taxation, 6(2), 29-40. https://doi.org/10.15640/ijat.v6n2a4

AlAdham, M. "Abd A., Abukhadijeh, M. A., \& Qasem, M. F. (2016). Tax Evasion and Tax Awareness Evidence from Jordan. International Business Research, 9(12), 65. https://doi.org/10.5539/ibr.v9n12p65

Alstadsæter, A., \& Jacob, M. (2013). The Effect of Awareness and Incentives on Tax Evasion. SSRN Electronic Journal. https://doi.org/10.2139/ssrn.2309856

Aribaba, F. O., Oladele, R., Ahmodu, A.-L. O., \& Yusuff, S. A. (2019). Tax policies and Entrepreneurship Sustainability in Ondo State, Nigeria. Journal of Global Entrepreneurship Research, 9(1). https://doi.org/10.1186/s40497-019-0168-0

Asrinanda, \& Diantimala, Y. (2018). The Effect of Tax Knowledge, Self Assessment System, and Tax Awareness on Taxpayer Compliance. International Journal of Academic Research in Business and Social Sciences, 8(10), 539-550. https://doi.org/10.6007/ijarbss/v8-i10/4762

Atawodi, O. W., \& Ojeka, S. A. (2012). Factors That Affect Tax Compliance among Small and Medium Enterprises (SMEs) in North Central Nigeria. International Journal of Business and Management, 7(12), 87-96. https://doi.org/10.5539/ijbm.v7n12p87 
Daniel, T., \& Faustin, G. (2019). Effect of Tax Incentives 0n The Growth of Small and Medium-Sized Enterprises (SMEs) in Rwanda: A case study of SMEs in Nyarugenge district. Journal of Accounting and Taxation, 11(5), 89-98. https://doi.org/10.5897/jat2019.0339

Elmi, M. A., Tirimba, O. I., \& Evans, K. (2015). Relationship between Tax Compliance Barriers and Government' s Revenue Generation at Gobonimo Market in Somaliland. International Journal of Business Management and Economic Research, 6(6), 380-399.

Eragbhe, E., \& Modugu, K. P. (2014). Tax Compliance Costs of Small and Medium Scale Enterprises in Nigeria. International Journal of Accounting and Taxation, 2(1), 63-87. www.aripd.org/ijat

Fagariba, C. J. (2016). Perceptions of Causes of SMEs and Traders Tax Evasion : A Case of Accra Metropolis , Ghana. Journal of Business \& Economic Management, 4(2), 017039. https://doi.org/10.5923/j.economics.20160602.04

Febriani, Y., \& Kusmuriyanto. (2015). Analisis Faktor-Faktor yang Mempengaruhi Kepatuhan Wajib Pajak. Accounting Analysis Journal, 4(4). https://doi.org/10.15294/aaj.v4i4.9112

Hamid, N. A., Noor, R. M., Zain, M. M., \& Bardai, B. (2010). Determinants of Successful Utilization of Tax Incentives in SMEs Manufacturing Sectors. CSSR 2010 - 2010 International Conference on Science and Social Research, October 2018, 1249-1254. https://doi.org/10.1109/CSSR.2010.5773728

Hastuti. (2014). Tax Awareness And Tax Education: A Perception Of Potential Taxpayers. International Journal of Business, Economics and Law, 5(1), 9.

Hohenwarter, A. D., \& Ll, M. (n.d.). The Compensation of Losses within Groups of Companies by Daniela Hohenwarter Summary of the Main Conclusions.

Kim, J. H., \& Im, C. C. (2017). The Study on The Effect and Determinants of Small-and Medium-Sized Entities Conducting Tax Avoidance. Journal of Applied Business Research, 33(2), 375-390.

Naicker, Y., \& Rajaram, R. (2018). Factors that Influence Tax Compliance of SMEs in South Africa. Acta Universitatis Danubius Administratio, 10(2), 94-111. http://journals.univdanubius.ro/index.php/administratio/article/download/5616/4898

Newman, W., Mwandambira, N., Charity, M., \& Ongayi, W. (2018). Literature Review on the Impact of Tax Knowledge on tax Compliance among Small Medium Enterprises in a Developing Country. Journal of Legal, Ethical and Regulatory Issues, 22(4), 1-15.

Nkwe, N. (2012). Tax Payers' Attitude and Compliance Behavior among Small Medium Enterprises (SMEs) in Botswana. Business and Management Horizons, 1(1), 113. https://doi.org/10.5296/bmh.v1i1.3486

Nuridayu Yunus, Rosiati Ramli, \& Norul Syuhada Abu Hassan. (2017). Tax Penalties and Tax Compliance of Small Medium Enterprises (SMEs) in Malaysia. International Journal of Business, Economics and Law, 12(1), 81-91. http://ijbel.com/wpcontent/uploads/2017/07/ACC-342.pdf

Nurkhin, A., Novanty, I., Muhsin, M., \& Sumiadji, S. (2018). The Influence of Tax Understanding, Tax Awareness and Tax Amnesty toward Taxpayer Compliance. Jurnal Keuangan Dan Perbankan, 22(2), 240-255. https://doi.org/10.26905/jkdp.v22i2.1678

Pamuji, A. R. (2014). Faktor-Faktor yang Mempengaruhi Kepatuhan Pemilik Usaha Mikro, Kecil, dan Menengah (Umkm) dalam Memenuhi Kewajiban Perpajakan (Studi pada Wajib Pajak Pemilik UMKM Di KPP Pratama Malang Selatan). Jurnal Mahasiswa Perpajakan, 3(1), 1-9.

Saad, N. (2014). Tax Knowledge, Tax Complexity and Tax Compliance: Taxpayers' View. Procedia - Social and Behavioral Sciences, 109(1), 1069-1075. https://doi.org/10.1016/j.sbspro.2013.12.590 
Savitri, E., \& Musfialdy. (2016). The Effect of Taxpayer Awareness, Tax Socialization, Tax Penalties, Compliance Cost at Taxpayer Compliance with Service Quality as Mediating Variable. Procedia - Social and Behavioral Sciences, 219, 682-687. https://doi.org/10.1016/j.sbspro.2016.05.051

Suyanto, S., \& Trisnawati, E. (2016). The Influence of Tax Awareness Toward Tax Compliance of Entrepreneurial Taxpayers and Celengan Padjeg Program as a Moderating Variable: A Case Study At The Pratama Tax Office Of Wonosari Town. Inferensi, 10(1), 47. https://doi.org/10.18326/infsl3.v10i1.47-68

Wicaksono, R. (2016). Faktor-Faktor yang Mempengaruhi Kepatuhan Wajib Pajak Usaha Mikro Kecil dan Menengah (UMKM) dalam Membayar Pajak Sesuai Pp No.46 Tahun 2013 pada UMKM di Kabupaten Bantul. Jurnal Fokus Bisnis, 15(2), 1-21. https://doi.org/10.1007/978-94-007-0753-5_2337 